\title{
An evaluation of the emergency care training workshops in the province of KwaZulu-Natal, South Africa
}

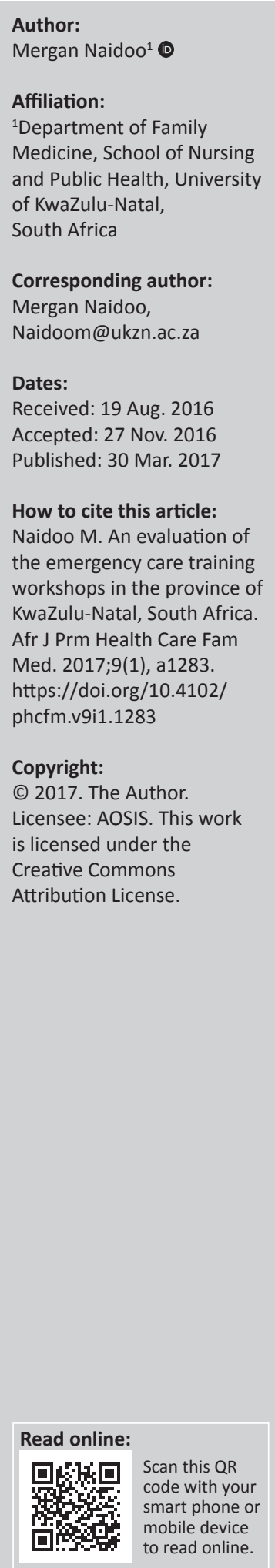

Background: Emergency care in South Africa is both complex and complicated which is further compromised by inadequately trained healthcare workers. Academic disciplines at the University of KwaZulu-Natal have run emergency care workshops for doctors and nurses providing primary emergency care, in the province for the last 14 years. This delivery of such training has evolved over time.

Objectives: The aim of this study was to evaluate the feedback and knowledge of participants attending the last nine workshops.

Methods: An evaluation questionnaire asked participants to assess the workshops held in the province and to rate their perceived improvement in knowledge. A multiple choice questionnaire was conducted in the last few workshops and was administered pre- and postworkshop. The data were extracted onto an Excel spreadsheet and analysed in Stata version 13. Outcome measures were generated using percentages. A paired $t$-test was used to compare knowledge scores. Open-ended questions were also used to identify areas for future improvement.

Results: The majority $(89.4 \%)$ of the participants worked in the primary emergency care setting. All participants found the quality of training, the facilitators and the training material good or excellent. Participants' perceived improvement in knowledge and skills and the objective measure of knowledge improved significantly $(p<0.001)$.

Conclusion: Emergency care education using a combination of inter-professional simulation and lecture-based teaching has the potential of contributing towards better educational outputs in both undergraduate and postgraduate curricula.

\section{Background}

In the province of KwaZulu-Natal (KZN), South Africa, there are 41 district hospitals, 11 regional hospitals and 3 tertiary hospitals that are expected to provide emergency medicine (EM) services to patients accessing care in the public sector. ${ }^{1}$ However, in 2016 only two district and three regional hospitals had emergency care specialists employed who were providing an emergency service. The other hospitals rely on medical officers and/or medical interns to provide the service with the assistance of emergency care nurse practitioners. Many of the staff do not have any formal emergency care training despite having to deal with a complex burden of disease. ${ }^{2}$ Emergency centres (ECs) in KZN are often faced with having to deal with a large burden of HIV patients, which could comprise up to $50 \%$ of all patients seen. ${ }^{3}$ These patients often present with complex medical problems affecting multiple organ systems and many need admission for stabilisation and definitive care. ${ }^{3}$ The combination of complex clinical presentations coupled with inadequately trained staff who provide services in most of the district and regional hospitals in KZN has the potential to compromise the quality of patient care.

Since 2002, the Department of Family Medicine at the University of KwaZulu-Natal (UKZN) has had a programme aimed at improving the skills of doctors and nurses providing primary emergency care in the province. From 2002 until 2011, the programme consisted of lectures followed by emergency skills training in the clinical skills laboratory at UKZN. However, in 2011 clinicians from the disciplines of Family Medicine, Emergency Medicine, Nursing, Paediatrics and Trauma Surgery collaborated to put together a modular based programme using a combination of short PowerPoint presentations and simulation-based training using low-fidelity methods because of the resource constraints that exist in the public healthcare environment. The idea 
behind the training was to identify and train two medical practitioners and two EC nurses based at hospitals and community healthcare centres $(\mathrm{CHCs})$ providing primary emergency care. This method of teaching has been evaluated as having a moderate quality of evidence by the World Health Organization (WHO) which strongly recommends that simulation-based teaching be introduced into health worker curricula. ${ }^{4}$ The $\mathrm{WHO}$ guideline further recommends that healthcare worker (HCW) education be provided using an inter-professional approach especially in resource-limited settings as this allows for more HCWs to be trained. ${ }^{4}$

Both these training methods were employed when developing the 10 modules for the 2-day programme. The 2-day programme was developed in 2011 after a group of three family physicians, three emergency care physicians, a surgeon and a nurse reviewed the existing programme and decided to focus on 10 core areas that make up the bulk of morbidity presenting to emergency departments in KZN. Different members of the team were asked to develop the core PowerPoint presentation lasting between 20 and 45 minutes and also develop the skills and simulation scenarios with checklists. The programme was developed along similar lines as the ESMOE (Essential Steps in the Management of Obstetric Emergencies) programme. ${ }^{5}$ Experts then presented their modules and peer review of the content and resources was provided by the group. The programme consisted on the following 10 modules: resuscitation and triage, trauma, common cardiac emergencies, common medical emergencies, sexual assault and ethics in the EC, an approach to the patient with a depressed level of consciousness, common paediatric emergencies, an approach to common poisons and toxins, HIV emergencies and interpreting common radiological investigations in the EC. Skills taught in the programme included resuscitation skills, airway management skills, managing unstable cardiac arrhythmias and immobilising a patient with a cervical spine injury. The South African Triage Scale was also introduced to HCWs and the training was reinforced by asking participants to triage simulated cases presented during small group discussions. ${ }^{6}$ Emergency simulations using case scenarios were used to facilitate learning in most of the modules. This involved dividing participants into small groups and then providing these groups with a scenario that they needed to manage using an inter-professional approach. The group was provided with feedback on the 'simulated patient' as they progressed. After the simulation was completed, reflection, peer feedback and facilitator feedback occurred. A scoring checklist was used in the simulations. In some instances, a volunteer from the participants was used as the simulated patient. The programme was then implemented in a decentralised fashion in the various districts in $\mathrm{KZN}$ and the manikins and equipment were loaned from the clinical skills laboratory at UKZN. EM Workshops were conducted in the following districts, viz. Ugu, Uthungulu, Umgungundlovu, Umkhanyakude, Zululand, Amajuba, iLembe and eThekwini between 2012 and 2016. Training initially took place in hospitals; however, this was found to be problematic as
HCWs were constantly called out of the workshop to attend to problems in the hospital so the venues were changed to external venues in 2014.

The aim of this study was to evaluate the feedback of participants attending the last nine workshops and to assess the written test administered pre- and post-workshops. To the author's best knowledge, no such evaluation of workshops has been provided to HCWs in the primary emergency care setting in South Africa.

\section{Methods}

Participants who were present for the entire workshop and who agreed to participate in the evaluation completed an evaluation questionnaire at the end of each workshop from 2013. Participants consisted of doctors and nurses providing emergency care at tertiary, regional and district hospitals as well as $\mathrm{CHCs}$ and primary healthcare clinics (PHCs). The feedback was used to improve the content of subsequent courses. Since 2015, a pre- and post-course knowledge test in the form of a multiple choice questionnaire (MCQ) was administered. The evaluation questionnaire was based on the ESMOE evaluation tool and the MCQ test was developed by the course coordinator based on the content of the module.

The evaluation questionnaire asked participants to assess the quality of training, the trainers, the course material, their confidence in using the course material in running similar courses in their own institutions, the content of the course and a perceived improvement in knowledge and skills pre- and post-course attendance. The MCQ consisted of 10 questions based on each module of the course. The questions were in a true and false format. A retrospective review of the responses of the evaluation questionnaires and the results of pre- and post-test written examination was performed.

The data were extracted onto an Excel spreadsheet and analysed in Stata version 13. Outcome measures generated included means, standard deviations and percentages. A paired $t$-test was used to compare perceived improvement in knowledge based on a rating scale and the knowledge scores from the MCQ test pre- and post-workshop. Significance was set at the $5 \%$ level, that is, $p<0.05$. Open-ended questions in the evaluation questionnaire were analysed and the commonest responses were thematically presented based on the responses received. Not all participants responded to these questions.

\section{Results}

Eleven 2-day workshops were held in various districts in KZN and 321 HCWs were trained. Between $61.56 \%(n=135)$ and $86.6 \%(n=278)$ completed various elements of the evaluation questionnaire. Seventy-two percent $(n=135)$ out of an eligible 187 participants completed the MCQ test. Some of the workshops involved HCWs from more than one district. Table 1 presents an outline of the various workshops held in the province over the last 5 years. 
TABLE 1: Outline of the emergency medicine training workshops done in KZN.

\begin{tabular}{|c|c|c|c|c|c|c|}
\hline \multirow[t]{2}{*}{$\overline{\text { Date }}$} & \multicolumn{2}{|c|}{ Participants } & \multirow[t]{2}{*}{ Venue } & \multirow[t]{2}{*}{ Districts covered } & \multirow[t]{2}{*}{ Course evaluation done } & \multirow[t]{2}{*}{ Pre-post-test } \\
\hline & Doctors & Nurses & & & & \\
\hline 25-27 June 2012 & 20 & 8 & Skills Laboratory Durban & eThekwini & No & No \\
\hline 26-28 Sept 2012 & 7 & 14 & Murchison Mission & Ugu & No & No \\
\hline 10-12 June 2013 & 22 & 0 & Northdale Hospital & uMgungundlovu & Yes & No \\
\hline 23-24 May 2014 & 24 & 2 & Ghost Mountain Inn & Umkhanyakude & Yes & No \\
\hline 1-2 August 2014 & 11 & 8 & Tsogo Sun Ulundi & Zululand & Yes & No \\
\hline 20-21 February 2015 & 25 & 36 & Skills Lab DURBAN & eThekwini/iLembe & Yes & Yes \\
\hline 26-27 June 2015 & 35 & 21 & Tsogo Sun Pietermaritzburg & uMgungundlovu/Harry Gwala/Umzinyathi & Yes & Yes \\
\hline 18-19 March 2016 & 14 & 21 & Salt Rock Hotel & llembe & Yes & Yes \\
\hline 6-7 May 2016 & 9 & 9 & St Michaels Beach Hotel & Ugu & Yes & Yes \\
\hline 22-23 July 2016 & 7 & 10 & Richards Bay Protea Hotel & Uthungulu & Yes & Yes \\
\hline Total & 184 & 137 & 11 venues & 11 districts & - & - \\
\hline
\end{tabular}

HCWs consisted of emergency room nurses and doctors and clinical or nursing managers. The majority of the staff $(65 \%)$ worked at district hospitals, $11.5 \%$ of staff were based at $\mathrm{CHCs}$ and PHCs and the remainder of the staff worked at regional or tertiary hospitals and the district office. Participation from HCWs based in rural districts were poor and this was often ascribed to poor staffing and long distances that needed to be travelled to get to the workshop. The majority $(89.4 \%)$ of the participants who completed the questionnaire worked in the primary emergency care setting as the regional hospitals were all combination regionaldistrict hospitals that provided a primary emergency care service. HCWs evaluated the programme using a scale between 1 and 5, with a score of 1 rated as poor, 2 as fair, 3 as average, 4 as good and 5 rated as excellent. Table 2 depicts the mean scores.

Most participants found the quality of training, the facilitators and the training material good or excellent. Participants expressed a willingness to use their new found knowledge by implementing changes in their own institutions either by training others or by changing their current practice. Responses to questions on whether they would train others in their institution revealed that $92.64 \%(N=231)$ found the course comprehensive enough to provide them with the confidence to train others at their institutions and $93.51 \%$ $(N=231)$ stated that they will be doing EM training at their own institutions.

Participants were asked to assess their improvement in knowledge and skills after attending the workshop. A paired $t$-test was used to analyse responses based on a scale of 0 (I have no knowledge or skill) to 5 (I can do this and I can teach others). Results are shown in Table 3.

The pooled results from all the workshops indicate that participants' felt that their knowledge and skills improved significantly across all modules $(p<0.001)$. The mean difference across all modules pre-workshop compared to post-workshop was -1.22 (95\% confidence interval: -1.45 ; -0.99), which was statistically significant. The results obtained via an MCQ administered at the last five workshops are listed in Table 4.
TABLE 2: Satisfaction with the training programme - Pooled analysis.

\begin{tabular}{lccc}
\hline Variable & $N$ & Mean & s.d. \\
\hline What is your overall impression of this training programme? & 235 & 4.64 & 0.56 \\
$\begin{array}{l}\text { How satisfied were you with the venue? } \\
\text { How satisfied were you with the organisation or the training }\end{array}$ & 278 & 4.57 & 0.65 \\
$\begin{array}{l}\text { programme? } \\
\text { How satisfied were you with the training material? }\end{array}$ & 236 & 4.58 & 0.62 \\
$\begin{array}{l}\text { How satisfied were you with the skills demonstrations/ } \\
\text { simulations? }\end{array}$ & 259 & 4.53 & 0.66 \\
\begin{tabular}{l} 
How satisfied were you with the facilitators? \\
\hline
\end{tabular} & 259 & 4.61 & 0.64 \\
\hline
\end{tabular}

$N$, Number of participants who filled in this section of the evaluation questionnaire; s.d., standard deviation.

TABLE 3: Change in knowledge and skills using a paired $t$-test: Pooled analysis.

\begin{tabular}{lllll}
\hline Module & Self-assessment & $N$ & Mean & s.d. \\
\hline Resuscitation and triage & Pre & 211 & 2.71 & 1.25 \\
& Post & 211 & 4.27 & 0.88 \\
Trauma & Pre & 211 & 2.79 & 1.21 \\
& Post & 211 & 4.02 & 1.03 \\
Cardiac emergencies & Pre & 207 & 2.60 & 1.22 \\
& Post & 207 & 3.89 & 0.96 \\
Medical emergencies & Pre & 207 & 2.85 & 1.18 \\
& Post & 207 & 3.96 & 1.04 \\
Ethics - sexual assault & Pre & 197 & 2.53 & 1.37 \\
& Post & 197 & 3.75 & 1.18 \\
Unconscious patient & Pre & 211 & 2.89 & 1.22 \\
Toxicology & Post & 211 & 4.05 & 1.03 \\
& Pre & 207 & 2.56 & 1.19 \\
Paediatrics & Post & 207 & 3.83 & 1.04 \\
& Pre & 208 & 2.73 & 1.16 \\
HIV emergencies & Post & 208 & 3.86 & 1.03 \\
& Pre & 212 & 2.64 & 1.20 \\
Radiology & Post & 212 & 3.86 & 1.03 \\
& Pre & 211 & 2.42 & 1.37 \\
\hline N & Post & 211 & 3.85 & 2.18 \\
\hline
\end{tabular}

$N$, Number of participants who filled in this section of the evaluation questionnaire; s.d., standard deviation.

Knowledge improved significantly post-workshops for both doctors and nurses with the mean score of nurses being higher than the mean score for doctors. The MCQ examination had 10 questions and the maximum mark was 10.

Participants were asked to list any suggestions they may have on how their knowledge and skills could be improved. The most common suggestions were (number of responses in brackets) the following: 
TABLE 4: Analysis of pre- and post-test results of the multiple choice question examination.

\begin{tabular}{lcccccc}
\hline Variable & $N$ & Mean & s.e.m. & s.d. & \multicolumn{2}{c}{$\begin{array}{c}\text { 95 Confidence } \\
\text { interval }\end{array}$} \\
\hline $\begin{array}{l}\text { Entire group } \\
\quad\end{array}$ & 135 & 4.02 & 0.14 & 1.63 & 3.75 & 4.30 \\
$\begin{array}{l}\text { Pre-test } \\
\text { Post-test }\end{array}$ & 135 & 6.12 & 0.14 & 1.64 & 5.84 & 6.40 \\
Nurses & & & & & & \\
$\quad$ Pre-test & 70 & 4.3 & 0.22 & 1.82 & 3.86 & 4.73 \\
Post-test & 70 & 6.63 & 0.19 & 1.58 & 6.25 & 7.01 \\
$\begin{array}{l}\text { Doctors } \\
\quad \text { Pre-test }\end{array}$ & 65 & 3.72 & 0.17 & 1.34 & 3.39 & 4.05 \\
$\quad$ Post-test & 65 & 5.57 & 0.19 & 1.53 & 5.18 & 5.95 \\
\hline
\end{tabular}

s.e.m., standard error of the mean; $N$, Number of participants who filled in this section of the evaluation questionnaire; s.d., standard deviation.

- Thank you, well done, I gained lots of knowledge. (94)

- Simulations should be done in the workplace to reinforce knowledge and skills. (42)

- Simulations should be done weekly. (20)

- Please provide accommodation. (15)

- These workshops should be conducted at each hospital. (13)

- Please conduct the workshop more often. (13)

- Develop an emergency care workshop for PHC nurses. (13)

- Add the skill of sub-cutaneous pacing. (10)

- More time is needed for this workshop. (10)

- Add a section on dermatology. (9)

\section{Ethical consideration}

Ethical approval to publish the findings of this evaluation was obtained from the UKZN Biomedical Research Ethics Committee (Reference BE 427/15). Funding for the training was obtained from the UKZN Medical Education Partnership Initiative (MEPI).

\section{Discussion}

The main study findings were participants rating the overall workshop as good or excellent and a significant improvement in knowledge and skills.

The bulk of the participants were from institutions which provided primary emergency care and this may have been achieved because of the decentralised programme. Although the project used a decentralised district-based model for training, the participation from rural districts was poor because of distances that needed to be travelled to get to the venue as well as poor staffing levels at rural district hospitals. The centralised model of training that is being used by the ESMOE programme in KZN may be a better suited model.? The ESMOE master trainer programme provides accommodation for participants in Durban, but this cost could be defrayed against the cost of venue hire and meal provision at rural sites. This would also assist some participants who requested that accommodation be made available.

The use of low-fidelity simulations was appreciated by all participants in contrast with the perception that simulationbased training is expensive. ${ }^{8}$ Low-fidelity simulation training in this setting required participants to volunteer to be patients and basic emergency equipment was provided for practice of some of the skills. High-fidelity training generally expects the simulation to replicate the real-life scenario to a greater extent and this is done using advanced training manikins that make use of sophisticated computer programmes with/ without the aid of a skilled technician. ${ }^{9}$ Simulation-based training allows for the acquisition of clinical expertise in a non-threatening environment that does not compromise patient safety. Experiential clinical learning in the real clinical environment is the gold standard for learning but comes at a risk to patient safety, whereas simulation-based training allows participants to practice, reflect, get feedback and repractice until satisfied with their competencies. ${ }^{8,9}$ Like many other interventions in medicine, simulation-based training has its roots in the aviation industry which reported a $90 \%$ reduction in collisions during adverse weather conditions when a 'primitive simulator' was used early in the 20th century. ${ }^{9}$ Anaesthesia and surgery were the first disciplines to use simulation-based training in their curricula, but this has now expanded to many other disciplines of medicine. ${ }^{9,10,11}$ The EM postgraduate programmes in the United States have in particular seen a significant growth of simulation-based training during the period 2003-2008. ${ }^{10}$ Many of these programmes use high-fidelity simulators ${ }^{10}$ in contrast with the low-cost simulations used in this programme.

The majority of the participants rated the overall workshop as good to excellent with similar sentiments made on the quality of the logistics, the facilitators, the simulations and the resource material provided. These findings are consistent with those of Mugford and colleagues ${ }^{12}$ who found similar results in the primary care setting in Australia. The workshop had its own evolutionary process with feedback from participants being used to improve subsequent courses. Using scenarios based on actual case studies from clinical practice allows one to improve content validity and hopefully make inferences to authentic patient clinical pathways. ${ }^{13}$ Simulation also allows one to develop clinical skills, reflective practice, procedural skills and to develop skills in identifying deficiencies in the process and organisation of clinical care especially when used in the workplace. ${ }^{13}$ Participants were encouraged to use their newly acquired skills in their places of work and many indicated that they will do so. Using the facilitator resources that were provided on their DVDs, they were encouraged to run these simulations in a real environment and identify gaps in terms of resources and process flows, which would then facilitate the development of quality improvement projects.

Participants' subjective assessment of their perceived knowledge showed significant improvement, which was then ratified when the pre- and post-test questionnaires were administered during the last few workshops. Based on Pratt's $\mathrm{s}^{14}$ nurturing perspective of teaching, one needs to acknowledge that effective teaching must respect adult learners' 'self-concept and self-efficacy' in assessing their knowledge and skills. A combination of lecture-based teaching that highlighted key points in very short presentations followed by simulation drills improved the short-term knowledge scores. This is consistent with other studies 
which found similar results when used to teach toxicology. ${ }^{15}$ Simulation-based training has also been found to improve knowledge retention. $8,9,11,15$ Clinical simulation can easily be adapted for a clinic or emergency room setting. This is a useful tool for maintaining expertise in core emergency skills, which may only be needed on rare occasions in the real world. It is important that the simulation format of introduction, drill execution, personal reflection and then feedback is used to reinforce knowledge and skills. The workshop allowed for a before and after drill to be performed, which allowed participants a practice run after feedback. Simulation would fit into the category of 'shows how' if one had to extrapolate this to Millers pyramid of clinical teaching. ${ }^{16}$ The training would satisfy formative training and could easily augment workintegrated learning. ${ }^{4}$ Many participants expressed a willingness to integrate simulation training in the clinical environment and this was encouraged as it has been shown to improve skills in the ESMOE programme in KZN.?

The baseline mean and post-test mean knowledge score for nurses was higher than that of doctors and this may be because of the fact that nurses tend to be employed in the public sector for much longer periods than doctors, ${ }^{17,18}$ which would have given them much better exposure to experiential learning in the emergency environment.

The inter-professional approach to training not only mimics the real work environment but also contributes towards improved teamwork and collaboration. ${ }^{11,19}$ Human simulation using standardised patients who were participants in the workshop worked well in many of the scenarios. Simulations are excellent for improving communication skills and interpersonal and profession skills. ${ }^{11}$ Using role definitions in scenarios further facilitated team work and outcomes in the simulations. It also allowed participants to appreciate the input from their colleagues from other disciplines. In the South African environment, one often finds this in junior doctors working with senior nurses who can provide invaluable input in a stressful emergency care environment.

\section{Limitations of the study}

The workshop content followed an evaluation, analysis and modification throughout the 4 years between 2012 and 2015 . In addition, the first few workshops were held at venues within the hospital and this created problems with participation and no formal evaluation was done of these courses. The programme was evaluated by the administrator of the course, and despite being anonymously filled in, one would expect that an element of bias may exist. No long-term assessment of an improvement in knowledge and skills was performed to indicate if the new knowledge would be retained. The impact on work place-based practice and on patient outcomes was also not evaluated.

\section{Conclusion}

Emergency care education using a combination of interprofessional simulation and lecture-based teaching has the potential of contributing towards better educational outputs for nurses and doctors working in the primary emergency care setting. It is recommended that such training be introduced in both undergraduate and postgraduate curricula. A recommendation would be that future workshops be run at centralised venues as these attract better participation and if funds permit, accommodation be provided for participants from remote and rural sites. The recommendation of developing an emergency care workshop specifically designed for PHC nurses has been actioned and is being rolled out in the eThekwini district. A follow-up study is being contemplated to contact participants to establish if the training led to changes in clinical practice.

\section{Acknowledgements}

This work was made possible by grant number: 5R24TW008863 from the President's Emergency Plan for AIDS Relief and the National Institutes of Health, U.S. Department of Health and Human Services. Its contents are solely the responsibility of the University of KwaZulu-Natal (UKZN) Medical Education Partnership Initiative (MEPI) programme and do not necessarily represent the official views of the government. Acknowledgement is also made to the various individuals from the Discipline of Family Medicine, Emergency Medicine Nursing, Surgery and Paediatrics at the University of KwaZulu-Natal and the KwaZulu-Natal Department of Health. Special thanks go to Dr M. Muzigaba and Ms A Sevakran for their assistance with data capture and analysis.

\section{Competing interests}

The author declares that there has been no financial or personal relationships that may have inappropriately influenced the writing of this article.

\section{References}

1. Department: Health Province of Kwazulu-Natal. Provincial hospitals listed by district Pietermaritzburg [homepage on the Internet]. 2016 [cited 2016 Feb 15 ]. Available from: http://www.kznhealth.gov.za/district1.htm

2. Hanewinckel R, Jongman HP, Wallis LA, Mulligan TM. Emergency medicine in Paarl, South Africa: A cross-sectional descriptive study. Int J Emerg Med. 2010;3(3):143-150. https://doi.org/10.1007/s12245-010-0185-9

3. Naicker B, Maharaj R. HIV in acute care: A review of the burden of HIV-associated presentations to an Emergency Department. S Afr Fam Pract. 2015;58:1-5. https://doi.org/10.1080/20786190.2015.1079027

4. World Health Organization. Transforming and scaling up health professionals education and training [homepage on the Internet]. Geneva: World Health Organisation Press; 2013 [cited 2016 Feb 15]. Available from: http://apps.who.int/ iris/bitstream/10665/93635/1/9789241506502_eng.pdf

5. Frank K, Lombaard H, Pattinson RC. Does completion of the Essential Steps in Managing Obstetric Emergencies (ESMOE) training package result in improved knowledge and skills in managing obstetric emergencies? S Afr J Obstet Gynaecol. 2009;15(3):94-99.

6. Gottschalk SB, Wood D, DeVries S, Wallis LA, Bruijns S, Cape Triage G. The cape triage score: A new triage system South Africa. Proposal from the Cape Triage Group. Emerg Med J. 2006;23(2):149-153. https://doi.org/10.1136/emj.2005.028332

7. Moran NF, Naidoo M, Moodley J. Reducing maternal mortality on a countrywide scale: The role of emergency obstetric training. Best Pract Res Clin Obstet Gynaecol. 2015;29(8):1102-1118. https://doi.org/10.1016/j.bpobgyn.2015.08.002

8. Al-Elq AH. Simulation-based medical teaching and learning. J Family Community Med. 2010;17(1):35-40. https://doi.org/10.4103/1319-1683.68787

9. Reznek M, Harter P, Krummel T. Virtual reality and simulation: Training the future emergency physician. Acad Emerg Med. 2002;9(1):78-87. https://doi.org/ 10.1111/j.1553-2712.2002.tb01172.x

10. Okuda $Y$, Bond $W$, Bonfante $G$, et al. National growth in simulation training within emergency medicine residency programs, 2003-2008. Acad Emerg Med. 2008;15(11):1113-1116. https://doi.org/10.1111/j.1553-2712.2008.00195.x 
11. McLaughlin SA, Doezema D, Sklar DP. Human simulation in emergency medicine training: A model curriculum. Acad Emerg Med. 2002;9(11):1310-1318. https:// training: A model curriculum. Acad Emerg $\mathrm{M}$.
doi.org/10.1111/j.1553-2712.2002.tb01593.x

12. Martin A, Owen $H$, Mugford B. Simulation training in emergency medicine: An important need for primary care training. Aust Fam Physician. 2004;33(4):279.

13. Bond WF, Lammers RL, Spillane LL, et al. The use of simulation in emergency medicine: A research agenda. Acad Emerg Med. 2007;14(4):353-363. https://doi. org/10.1111/j.1553-2712.2007.tb02021.x

14. Pratt DD. Five perspectives on teaching in adult and higher education. ERIC Melbourne: Krieger Publishing Co; 1998.

15. Maddry JK, Varney SM, Sessions D, et al. A comparison of simulation-based education versus lecture-based instruction for toxicology training in emergency medicine residents. J Med Toxicol. 2014;10(4):364-368. https://doi.org/10.1007/s13181-014-0401-8
16. Norcini JJ. $A B C$ of learning and teaching in medicine - Work based assessment. BMJ. 2003;326(7392):753-755. https://doi.org/10.1136/bmj.326.7392.753

17. Chopra M, Lawn JE, Sanders D, et al. Achieving the health Millennium Development Goals for South Africa: Challenges and priorities. Lancet. 2009;374(9694):10231031. https://doi.org/10.1016/S0140-6736(09)61122-3

18. Ross A, Reid $\mathrm{S}$. The retention of community service officers for an additional year at district hospitals in KwaZulu-Natal and the Eastern Cape and Limpopo provinces. S Afr Fam Pract. 2009;51(3):249-253. https://doi.org/10.1080/20786 204.2009.10873856

19. Shapiro M, Morey J, Small S, et al. Simulation based teamwork training for emergency department staff: Does it improve clinical team performance when emergency department staff: Does it improve clinical team performance when 2004;13(6):417-21. https://doi.org/10.1136/qshc.2003.005447 